\title{
Depressive symptoms in patients diagnosed with benign prostatic hyperplasia
}

\author{
Barbara Pietrzyk • Magdalena Olszanecka-Glinianowicz • \\ Aleksander Owczarek · Tomasz Gabryelewicz • \\ Agnieszka Almgren-Rachtan • Andrzej Prajsner · Jerzy Chudek
}

Received: 5 November 2014 / Accepted: 26 January 2015 / Published online: 12 February 2015

(C) The Author(s) 2015. This article is published with open access at Springerlink.com

\begin{abstract}
Background Symptoms of depression are common in patients diagnosed with benign prostatic hyperplasia $(\mathrm{BPH})$ and are usually a reaction to deterioration of health, severity of lower urinary tract symptoms, and erectile dysfunction. The aim of this observational study was to evaluate the prevalence of depressive symptoms in patients diagnosed with BPH and factors affecting their occurrence in a large Polish cohort.

Patients and methods Four thousand thirty-five men $(4,035)$ diagnosed with BPH participated in the survey (age $65 \pm 8$ years). The occurrence of symptoms of depression was assessed using the Beck depression inventory, severity of lower urinary tract symptoms (LUTS) on the basis of the international prostate symptoms score, and erectile dysfunction using the international index of erectile function (IIEF-5).

Results Depressive symptoms were found in $22.4 \%$ of patients (mild in $20.8 \%$ and moderate/severe in $1.6 \%$ ).
\end{abstract}

\footnotetext{
B. Pietrzyk · J. Chudek $(\bowtie)$

Pathophysiology Unit, Department of Pathophysiology, Medical Faculty in Katowice, Medical University of Silesia, 18 Medyków Street, 40-752 Katowice, Poland

e-mail: chj@poczta.fm
}

\section{Olszanecka-Glinianowicz}

Health Promotion and Obesity Management Unit, Department of Pathophysiology, Medical Faculty in Katowice, Medical University of Silesia, 18 Medyków Street, 40-752 Katowice, Poland

e-mail: magols@esculap.pl

\section{A. Owczarek}

Division of Statistics, Department of Instrumental Analysis, Faculty of Pharmacy and Laboratory Medicine in Sosnowiec, Medical University of Silesia, Ostrogórska Street 30,

41-200 Sosnowiec, Poland
Erectile dysfunction was found in $71.9 \%$ of patients. Monotherapy for BPH was prescribed to $50.9 \%$ of patients (mostly ARA-selective $\alpha 1$-selective alpha-adrenolytic-47.5\%), while polytherapy (ARA with a 5-alpha reductase inhibitor-5 $5 \mathrm{RI}$ ) to $47.9 \%$. Logistic regression analysis showed a bidirectional relation between the occurrence of depressive symptoms and erectile dysfunction. The occurrence of both depressive symptoms and erectile dysfunction was related to severity of LUTS, nocturia, the use of $5 \alpha$ RI, comorbidity, and sedentary life style.

Conclusions Prevalence of depressive symptoms in patients diagnosed with BPH is associated with severity of LUTS, erectile dysfunction, nocturia, BPH pharmacother-

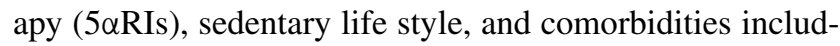
ing obesity.

Keywords Depressive symptoms - Benign prostatic hyperplasia $\cdot$ Erectile dysfunction $\cdot$ Risk factors $\cdot$ Cohort study

\section{T. Gabryelewicz}

Department of Neurodegenerative Disorders, Mossakowski

Medical Research Centre Polish Academy of Sciences,

Pawińskiego Street 5, 02-106 Warsaw, Poland

A. Almgren-Rachtan

Department of Pharmacovigilance, Europharma Rachtan Co.Ltd, Krzywa Street 6, 40-061 Katowice, Poland

\footnotetext{
A. Prajsner

Department of Urology, Medical Faculty in Katowice, Medical University of Silesia, Medyków Square 1, 41-221 Sosnowiec, Poland
} 


\section{Introduction}

The prevalence of benign prostatic hyperplasia $(\mathrm{BPH})$ increases gradually from the age of 50-80 years old at an incidence of $80 \%$ [1]. Lower urinary tract symptoms (LUTS) affect about $70 \%$ of men aged 80 years, and more than half of them seek medical consultation due to symptomatic BPH [2]. Considering the above data, it can be assumed that in Poland, approximately two million men suffer from LUTS related to BPH. However, there are no reliable data concerning the prevalence of BPH and LUTS related to $\mathrm{BPH}$ in the general Polish population. The results of the PolSenior study have shown that one in every four men aged 65 years and over is treated for BPH [3].

During the last decade, an association between the occurrence of LUTS (frequent urination, urgent urination, and weakened urine flow) related to BPH and sexual dysfunction, including libido, erectile, and ejaculation disturbances, as well as decreased satisfaction with sexual life has been described [4-6]. In men with severe LUTS, the risk of ejaculation and erectile dysfunction is doubled and the risk of painful ejaculation is sixfold greater than in men without LUTS [8-10]. Some $83 \%$ of men 50 years or older maintain sexual activity. Erectile dysfunction (ED) decreases self-esteem and has a negative impact on relationships [4, 11] which may be attributed to depressive symptom (DSs) development. It was also shown that ED may increase the risk of attempted suicide in men [11].

Additional risk factors for DSs development in subjects diagnosed with BPH are sleep disturbances related to nocturia, impairment of daily functioning caused by LUTS severity, as well as fear of developing prostate cancer and surgical procedures $[5,7]$.

It has also been suggested that adverse effects of drugs used for BPH treatment and surgical procedures are risk factors for both ED and DSs development. Use of inhibitors of 5- $\alpha$ reductase $(5 \alpha \mathrm{RI})$ may be a cause of ED [12, 13], and selective $\alpha_{1}$-adrenergic receptor antagonists (ARA) may impair ejaculation [14]. Contradictorily, it was also found that the quality of life significantly improve in patients treated for BPH with $5 \alpha \mathrm{RI}$ and ARA during the 4-year follow-up [15]. The decrease of LUTS severity and discomfort related to LUTS as well as improvement of the quality of life and increased satisfaction with life was also shown after 6 months of BPH treatment with $5 \alpha$ RI [16].

The prevalence of DSs and their influence in subjects diagnosed with BPH in Poland has not been assessed, yet. Therefore, the aim of this observational study was to evaluate the prevalence of depressive symptoms in patients diagnosed with BPH and factors influencing their occurrence in a large Polish cohort.

\section{Methods}

Patients and study design

In this observational survey, 4,035 men diagnosed with BPH were interviewed nationwide from November 2012 to Jun 2013 by 206 urologists from specialist outpatient clinics. Polish doctors participating in the study were recruited by medical representatives, and each of them conducted questionnaire interviews with a group of 15-30 consecutive patients diagnosed with $\mathrm{BPH}$ referred to the clinic.

The study procedures were in accordance with the ethical standards and the Helsinki Declaration of 1975, as revised in Seoul during 2008. As the questionnairebased survey did not fulfil the criterion of a medical experiment, Bioethics Committee approval was not required.

The inclusion criterion was age over 40 years and BPH diagnosis. The exclusion criteria included dementia, deafness, active psychiatric disorders, mood disorders in medical history, and diagnosed prostate cancer. PSA was a part of routine clinical management, but was not reported. BPH diagnosis was based on medical history, the presence of LUTS, and results of DRE (digital rectal examination) tests and sonography. Characteristics of the surveyed population are summarised in Table 1.

The questionnaire using in this study included demographic data (age, education level, place of residence, marital status, source of income), anthropometric measurements (body mass, height and waist circumference), lifestyle data (smoking, alcohol consumption, physical activity), and medical history (duration of BPH, duration of LUTS, pharmacotherapy used in treatment of $\mathrm{BPH}$, pharmacotherapy used in treatment of ED, severity of LUTS before using the current pharmacotherapy, current severity of LUTS, past transurethral resection of the prostate-TURP, and comorbidities).

The occurrence of DSs was assessed using the Beck Depression Inventory (BDI) in Polish version [17], severity of LUTS on the basis of the international prostate symptoms score (IPSS) and ED using the international index of erectile function (IIEF-5). The Polish versions of IPSS and IIEF-5 questionnaires were validated by the Polish Society of Urology.

Data analysis

The requisition of data was entered automatically with a specific form (Microsoft Office Access). Patients records $(N=53)$ with the diagnosis of prostate cancer were initially excluded. The percentage of missing data was less 
Table 1 Baseline characteristics of the study group-4,035 patients diagnosed with benign prostatic hyperplasia (BPH)

\begin{tabular}{|c|c|}
\hline Age [years] & $\begin{array}{l}65 \pm 8 \\
\text { (range 40-92 }\end{array}$ \\
\hline \multicolumn{2}{|l|}{ Age groups $[\mathrm{n}(\%)]$} \\
\hline$\leq 60$ years & $1,113(27.6)$ \\
\hline $61-80$ years & $2,818(69.8)$ \\
\hline$>80$ years & $104(2.6)$ \\
\hline \multicolumn{2}{|l|}{ Place of residence $[\mathrm{n}(\%)]$} \\
\hline Rural areas & $447(11.1)$ \\
\hline City with population $<50,000$ & $920(22.8)$ \\
\hline City with population $50,000-200,000$ & $1,678(41.6)$ \\
\hline City with population $>200,000$ & $990(24.5)$ \\
\hline \multicolumn{2}{|l|}{ Education $[\mathrm{n}(\%)]$} \\
\hline Primary & $331(8.2)$ \\
\hline Vocational & $1,393(34.7)$ \\
\hline Secondary & $1,600(39.6)$ \\
\hline Higher & $711(17.5)$ \\
\hline \multicolumn{2}{|l|}{ Marital status $[\mathrm{n}(\%)]$} \\
\hline Married & $2,975(73.8)$ \\
\hline Widowed/single & $1,060(26.2)$ \\
\hline \multicolumn{2}{|l|}{ Labour activity $[\mathrm{n}(\%)]$} \\
\hline Professionally active & $1,758(43.7)$ \\
\hline Unemployed & $172(4.3)$ \\
\hline Annuity & $376(9.4)$ \\
\hline Pension & $1,711(42.5)$ \\
\hline Other & $8(0.1)$ \\
\hline Nutritional status $[\mathrm{n}(\%)]$ & $28.4 \pm 3.8$ \\
\hline Normal weight & $572(14.2)$ \\
\hline Overweight & $2,297(56.9)$ \\
\hline Obese & $1,166(28.9)$ \\
\hline Waist circumference $[\mathrm{cm}]$ & $96 \pm 12$ \\
\hline Visceral obesity $[\mathrm{n}(\%)]$ & $2,147(53.5)$ \\
\hline \multicolumn{2}{|l|}{ Physical activity [n(\%)] } \\
\hline Less than 30 min a day & $2,671(66.2)$ \\
\hline $30-60$ min a day & $995(24.6)$ \\
\hline More than 60 min a day & $369(9.2)$ \\
\hline \multicolumn{2}{|l|}{ Alcohol consumption $[\mathrm{n}(\%)]$} \\
\hline Frequent (at least three times a week) & $760(18.8)$ \\
\hline Seldom & $2,360(58.5)$ \\
\hline No & $915(22.7)$ \\
\hline \multicolumn{2}{|l|}{ Cigarettes smoking } \\
\hline Currently $[\mathrm{n}(\%)]$ & $1,203(29.8)$ \\
\hline The extent of exposure [pack-years] & $24.0 \pm 12.8$ \\
\hline In the past $[\mathrm{n}(\%)]$ & $991(24.5)$ \\
\hline
\end{tabular}

than $3 \%$, and those entries were not removed from the analysis, as missing data were at random.

Nutritional status was assessed on the basis of BMI according to WHO criteria (underweight was diagnosed with values $<18.5 \mathrm{~kg} / \mathrm{m}^{2}$, overweight $25-29.9 \mathrm{~kg} / \mathrm{m}^{2}$ and obesity $\geq 30 \mathrm{~kg} / \mathrm{m}^{2}$ ) [18]. Visceral obesity was diagnosed by measuring waist circumference according to the IDF criteria for Caucasians ( $\geq 94 \mathrm{~cm}$ for men) [19].

The occurrence of depressive symptoms was scored on the results of BDI: $12-26$ points-mild and $>26$ pointsmoderate and severe group [20]. The severity of LUTS was classified on the basis of the IPSS scale as: mild (0-7 pts.), moderate (8-19 pts.), and severe (20-35 pts.) [21]. ED was diagnosed at the values of the IIEF-5 $\leq 21$ pts. [22].

Statistical analysis

Statistical analysis was performed using the STATISTICA 10.0 PL software package (StatSoft Krakow, Poland) and MedCalc v. 14.8.1 (MedCalc Software bvba, Ostend, Belgium).

An analysis was performed of respondents' age structure, education, marital status, nutritional status, visceral obesity, physical activity level, current severity of LUTS, period of current BPH treatment, current pharmacotherapy for $\mathrm{BPH}$, comorbidities, ED, and DSs.

The data collected with regard to DSs and ED were analysed according to age, education level, marital status, alcohol consumption, physical inactivity, comorbidities including obesity, severity of LUTS, treatment with inhibitor $5-\alpha$ reductase or anticholinergic medications, TURP history, nocturia, ED, or DSs, respectively.

Values of variables were presented as percentages and mean values with SD. Separate groups were compared using the $\chi^{2}$ test and $\chi^{2}$ test for trend and $t$ Student test for independent variables, and post hoc Tukey's test. The odds ratios for factors influencing ED and DSs were calculated based on the stepwise backward multiple logistic regression analysis. Multicollinearity has been check during the logistic regression procedure based on condition numbers (CN). The rule of thumb with $\mathrm{CN}$ greater than 15 has been used to remove correlated factors. A $p<0.05$ was considered as statistically significant.

\section{Results}

Characteristics of the surveyed group

The surveyed group was dominated by respondents aged 61-80 years, the medium city dweller, with secondary education, married, and professionally active or pensioner (Table 1).

$66.2 \%$ responders declare sedentary life style, $18.8 \%$ frequent alcohol consumption, $29.8 \%$ smoking currently, and $24.5 \%$ had in the past (Table 1).

Obesity according to WHO criteria was diagnosed in $28.9 \%$ responders, and visceral obesity according to IDF 
Table 2 Severity of lower urinary tract symptoms (LUTS), therapy of benign prostatic hyperplasia (BPH), coexisting diseases, depression, erectile dysfunction, and nocturia in 4,035 patients with BPH

\begin{tabular}{|c|c|}
\hline Severity of LUTS before treatment [pts.] & $16.8 \pm 5.9$ \\
\hline Mild [n(\%)] & $123(3.0)$ \\
\hline Moderate $[\mathrm{n}(\%)]$ & $2,651(65.7)$ \\
\hline Severe $[\mathrm{n}(\%)]$ & $1,261(21.3)$ \\
\hline Severity of LUTS currently [pts.] & $10.2 \pm 5.7$ \\
\hline Mild [n(\%)] & $1,774(44.0)$ \\
\hline Moderate $[\mathrm{n}(\%)]$ & $1,972(48.8)$ \\
\hline Severe $[\mathrm{n}(\%)]$ & $289(7.2)$ \\
\hline \multicolumn{2}{|l|}{ Period of treatment for BPH $[\mathrm{n}(\%)]$} \\
\hline Less than one year & $861(21.4)$ \\
\hline $1-2$ years & $1,044(25.9)$ \\
\hline $3-5$ years. & $1,056(26.2)$ \\
\hline More than 5 years. & $1,074(26.5)$ \\
\hline \multicolumn{2}{|l|}{ Current BPH pharmacotherapy $[\mathrm{n}(\%)]$} \\
\hline Monotherapy & $2,052(50.9)$ \\
\hline $\begin{array}{l}\alpha_{1} \text {-selective adrenergic receptor antagonist } \\
\text { (ARA) }\end{array}$ & $1,918(47.5)$ \\
\hline $5 \alpha$ reductase inhibitor $(\mathrm{I} 5 \alpha \mathrm{R})$ & $134(3.3)$ \\
\hline Polytherapy & $1,931(47.9)$ \\
\hline $\mathrm{ARA}+\mathrm{I} 5 \alpha \mathrm{R}$ & $1,623(40.2)$ \\
\hline ARA $+\mathrm{I} 5 \alpha \mathrm{R}+$ anticholinergic & $308(7.6)$ \\
\hline No pharmacotherapy (patients after TURP) & $52(1.3)$ \\
\hline Past TURP [n(\%)] & $52(1.3)$ \\
\hline \multicolumn{2}{|l|}{ Comorbidities } \\
\hline Coronary artery disease $[\mathrm{n}(\%)]$ & $742(18.4)$ \\
\hline Past myocardial infarction $[\mathrm{n}(\%)]$ & $340(8.5)$ \\
\hline Heart failure $[\mathrm{n}(\%)]$ & $108(2.7)$ \\
\hline Diabetes $[\mathrm{n}(\%)]$ & $669(16.7)$ \\
\hline Past stroke episode [n(\%)] & $129(3.2)$ \\
\hline Hypertension $[\mathrm{n}(\%)]$ & $2,170(53.6)$ \\
\hline Chronic kidney disease [n(\%)] & $48(1.2)$ \\
\hline Dyslipidaemia [n(\%)] & $712(17.5)$ \\
\hline Erectile dysfunction $[\mathrm{n}(\%)]$ & $2,900(71.9)$ \\
\hline Depression symptoms: & $904(22.4)$ \\
\hline Mild [n(\%)] & $840(20.8)$ \\
\hline Moderate/severe $[\mathrm{n}(\%)]$ & $64(1.6)$ \\
\hline Nocturia $[\mathrm{n}(\%)]$ & $2,554(63.3)$ \\
\hline
\end{tabular}

criteria was diagnosed in $53.5 \%$ (Table 1). Comorbidities were reported in $83.4 \%$ of the surveyed group. The most common comorbidities were hypertension (53.6\%), coronary artery disease $(18.4 \%)$, dyslipidaemia $(17.6 \%)$, and type 2 diabetes $(16.7 \%$ )_-Table 2 .

Medical history of BPH and its treatment

More than half of the patients were treated for BPH longer than 3 years (Table 2). Transurethral resection of the prostate (TURP) was performed in $1.3 \%$ of the surveyed population, and pharmacotherapy was not prescribed to these subjects.

Currently, more than half of patients were on monotherapy, mostly with ARA (47.5\% of surveyed population). Polytherapy was prescribed for $47.9 \%$ of the surveyed

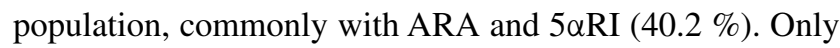
$7.6 \%$ of the surveyed population was treated with muscarinic receptor agonists (MRA) as a part of polytherapy (the third drug)—Table 2.

Before starting the therapy for BPH, $65.7 \%$ of surveyed subjects presented moderate and $21.3 \%$ severe LUTS. Current pharmacotherapy was associated with decreased frequency of moderate or severe symptoms by $66 \%$ (Table 2). Nocturia symptoms had been found in $63.3 \%$ surveyed population.

\section{Erectile dysfunction}

ED based on IIEF-5 was diagnosed in $71.9 \%$ of the surveyed population (in all after TURP), and $30.2 \%$ were treated for ED (Table 2).

The prevalence of ED in relation to demographic and clinical factors is shown in Table 3 . The statistical analysis revealed that $\mathrm{ED}$ occurrence was related to increased age, low education level, widowed or single marital status, sedentary life style, abstinence from or infrequent alcohol consumption, comorbidities (such as obesity, visceral obesity, past myocardial infarction or stroke, heart failure, hypertension, diabetes, and chronic kidney disease), length of time of BPH pharmacotherapy, polytherapy for BPH, history of TURP, LUTS severity, nocturia, and occurrence of moderate or severe DSs (Table 3). The association between ED and severity of DSs presents Fig. 1.

A backward model of multivariate logistic regression analysis demonstrated that the most important factors associated with the occurrence of ED were as follows: past cardiovascular episodes, heart failure, and depression. Therapy with inhibitors of 5-alpha reductase had negative effects, while the use of anticholinergic drugs was related to less frequent ED. Among factors that reduce the prevalence of ED were as follows: being married, higher education level, and frequent alcohol consumption (Fig. 5).

Depressive symptoms

DSs were found in $22.4 \%$ of the surveyed population, including mild symptoms in $20.8 \%$ and moderate/severe symptoms in $1.6 \%$. The prevalence of DSs in relation to demographic and clinical factors is shown in Table 3.

Statistical analysis revealed that DSs occurrence and severity were related to older age, lower education level, widowed or single marital status, sedentary life style, comorbidities (such as obesity, visceral obesity, coronary 
Table 3 Frequency of erectile dysfunction and depressive symptoms in relation to sociodemographic and clinical factors in 4,035 patients with benign prostatic hyperplasia

\begin{tabular}{|c|c|c|c|}
\hline & \multirow{2}{*}{$\begin{array}{l}\text { Erectile dysfunction } \\
\%\end{array}$} & \multicolumn{2}{|c|}{ Depressive symptoms } \\
\hline & & Mild \% & Moderate or severe $\%$ \\
\hline \multicolumn{4}{|l|}{ Age groups } \\
\hline$\leq 60$ years & 56.0 & 15.8 & 0 \\
\hline $61-80$ years & 77.2 & 22.8 & 2.1 \\
\hline$>80$ years & 100 & 19.2 & 3.8 \\
\hline \multicolumn{4}{|l|}{ Education } \\
\hline Primary & 85.4 & 52.0 & 7.2 \\
\hline Vocational & 70.1 & 20.1 & 2.0 \\
\hline Secondary & 72.3 & 18.5 & 0.7 \\
\hline Higher & 68.2 & 12.9 & 0 \\
\hline \multicolumn{4}{|l|}{ Marital status } \\
\hline Married & 67.3 & 15.2 & 0.7 \\
\hline Widowed/single & 89.3 & 36.6 & 4.1 \\
\hline \multicolumn{4}{|l|}{ Nutritional status } \\
\hline Normal weight & 63.8 & 16.2 & 1.4 \\
\hline Overweight & 68.3 & 16.9 & 0.9 \\
\hline Obese & 83.1 & 30.9 & 3.1 \\
\hline \multicolumn{4}{|l|}{ Visceral obesity } \\
\hline Yes & 79.1 & 23.7 & 1.7 \\
\hline No & 63.7 & 17.7 & 1.5 \\
\hline \multicolumn{4}{|l|}{ Physical activity } \\
\hline$<30$ min a day & 76.2 & 24.9 & 1.9 \\
\hline $30-60 \min$ a day & 65.2 & 12.5 & 1.2 \\
\hline$>60$ min a day & 58.7 & 14.1 & 0 \\
\hline \multicolumn{4}{|l|}{ Cigarette smoking } \\
\hline Ever smokers & 72.3 & 21.5 & 1.5 \\
\hline Non-smokers & 71.4 & 20.2 & 1.6 \\
\hline \multicolumn{4}{|l|}{ Alcohol consumption } \\
\hline Frequent & 59.7 & 23.2 & 4.2 \\
\hline Seldom/abstinent & 74.7 & 20.3 & 1.0 \\
\hline \multicolumn{4}{|l|}{ Current severity of LUTS } \\
\hline Mild & 48.5 & 7.7 & 0 \\
\hline Moderate & 89.2 & 26.0 & 1.6 \\
\hline Severe & 97.2 & 66.4 & 11.1 \\
\hline \multicolumn{4}{|l|}{ Period of BPH treatment } \\
\hline$<1$ year & 29.4 & 6.0 & 0 \\
\hline $1-2$ years & 68.1 & 14.6 & 0.8 \\
\hline $3-5$ years & 88.6 & 26.5 & 2.3 \\
\hline$>5$ years & 93.2 & 33.1 & 3.0 \\
\hline \multicolumn{4}{|l|}{ BPH treatment } \\
\hline Monotherapy & 55.8 & 10.3 & 1.2 \\
\hline Polytherapy & 88.5 & 31.7 & 2.0 \\
\hline$\alpha-1$ adrenergic receptor antagonist (ARA) & 54.4 & 10.0 & 0.8 \\
\hline $5-\alpha$ reductase inhibitor $(\mathrm{I} 5 \alpha \mathrm{R})$ & 75.8 & 14.9 & 6.0 \\
\hline $\mathrm{ARA}+\mathrm{I} 5 \alpha \mathrm{R}$ & 89.4 & 30.8 & 1.0 \\
\hline $\mathrm{ARA}+\mathrm{I} 5 \alpha \mathrm{R}+$ muscarinic receptor agonist & 89.1 & 33.8 & 6.5 \\
\hline No pharmacotherapy (past TURP) & 100 & 44.1 & 7.7 \\
\hline \multicolumn{4}{|l|}{ Comorbidities } \\
\hline Coronary artery disease & & & \\
\hline
\end{tabular}


Table 3 continued

\begin{tabular}{|c|c|c|c|}
\hline & \multirow{2}{*}{$\begin{array}{l}\text { Erectile dysfunction } \\
\%\end{array}$} & \multicolumn{2}{|c|}{ Depressive symptoms } \\
\hline & & Mild \% & Moderate or severe $\%$ \\
\hline Yes & 72.4 & 31.8 & 3.2 \\
\hline No & 71.8 & 18.3 & 1.2 \\
\hline \multicolumn{4}{|c|}{ Past myocardial infarction } \\
\hline Yes & 85.9 & 43.5 & 5.9 \\
\hline No & 70.6 & 18.7 & 1.2 \\
\hline \multicolumn{4}{|l|}{ Heart failure } \\
\hline Yes & 96.3 & 59.3 & 14.8 \\
\hline No & 71.2 & 19.8 & 1.2 \\
\hline \multicolumn{4}{|l|}{ Diabetes } \\
\hline Yes & 79.6 & 35.9 & 4.2 \\
\hline No & 70.3 & 17.8 & 1.1 \\
\hline \multicolumn{4}{|l|}{ Past stroke episode } \\
\hline Yes & 96.9 & 31.0 & 6.2 \\
\hline No & 71.1 & 20.5 & 1.4 \\
\hline \multicolumn{4}{|l|}{ Hypertension } \\
\hline Yes & 74.7 & 19.7 & 1.1 \\
\hline No & 68.6 & 22.1 & 2.1 \\
\hline \multicolumn{4}{|l|}{ Chronic kidney disease } \\
\hline Yes & 100 & 66.7 & 25.0 \\
\hline No & 71.5 & 20.3 & 1.3 \\
\hline \multicolumn{4}{|l|}{ Depression symptoms } \\
\hline Moderate or severe & 97.1 & - & - \\
\hline Mild & 89.8 & - & - \\
\hline No symptoms & 62.7 & - & - \\
\hline \multicolumn{4}{|l|}{ Erectile dysfunction } \\
\hline Yes & - & 27.5 & 2.1 \\
\hline No & - & 7.6 & 0.4 \\
\hline \multicolumn{4}{|l|}{ Nocturia } \\
\hline Yes & 79.3 & 27.4 & 2.2 \\
\hline No & 59.2 & 9.4 & 0.5 \\
\hline
\end{tabular}

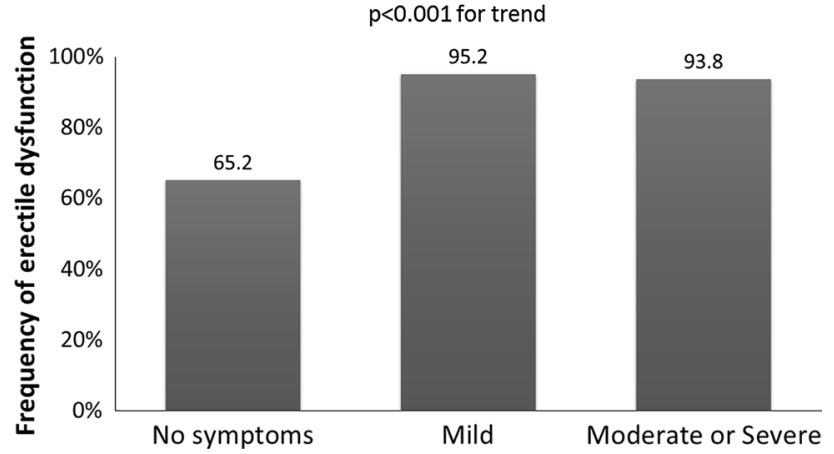

Fig. 1 Frequency of erectile dysfunction in relation to the occurrence and severity of depressive symptoms in patients diagnosed with benign prostatic hyperplasia (BPH)

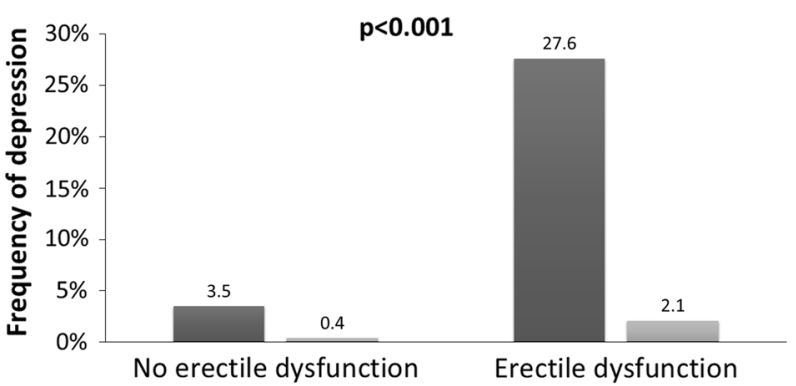

nild depressive symptoms Moderate or Severe depressive symptoms

Fig. 2 Frequency of depressive symptoms in relation to prevalence of erectile dysfunction 
Fig. 3 Structure of pharmacotherapy for $\mathrm{BPH}$ in relation to the occurrence of depressive symptoms in 4,035 patients diagnosed with $\mathrm{BPH}$
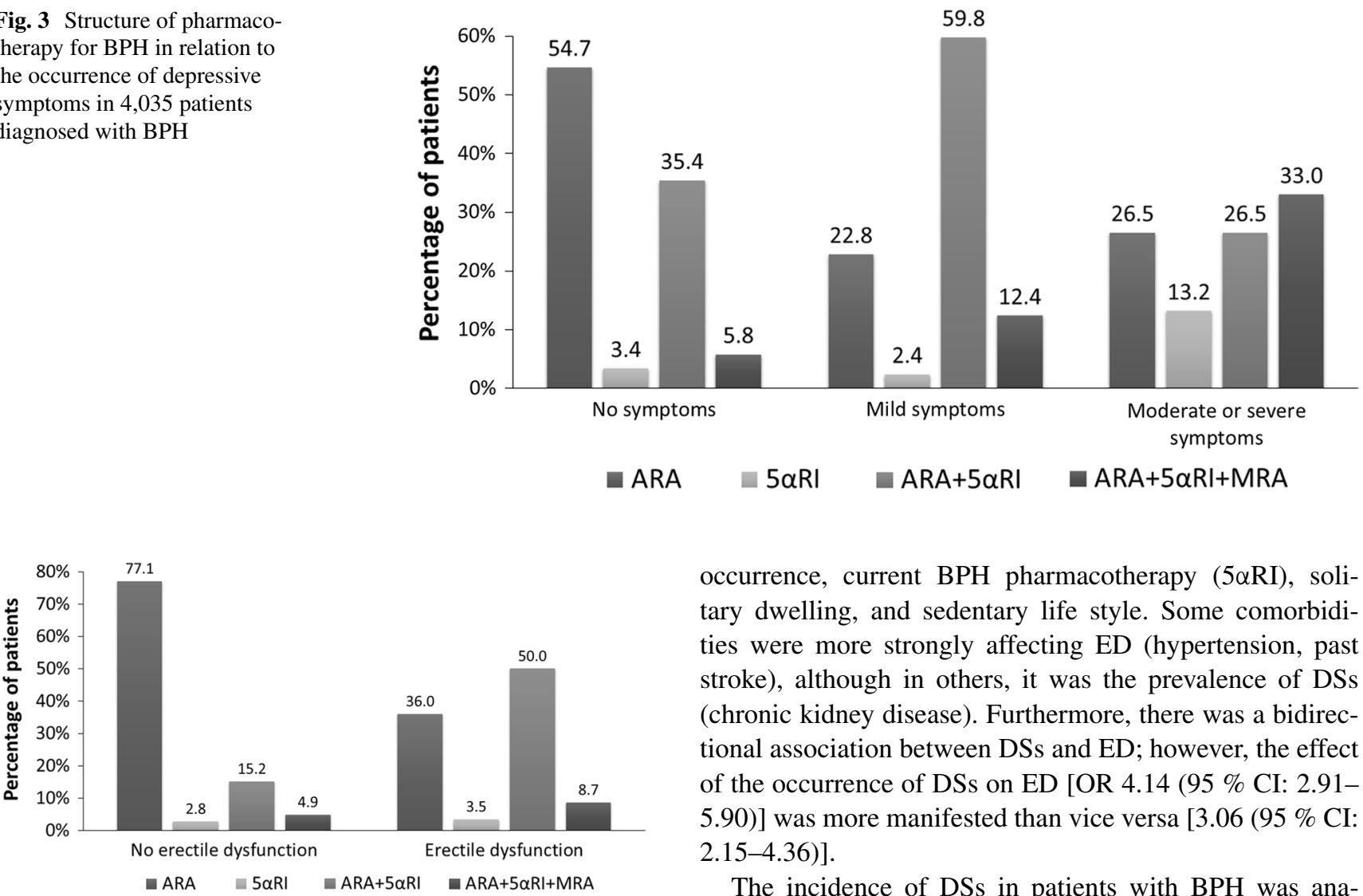

Fig. 4 Structure of pharmacotherapy for BPH in relation to the occurrence of erectile dysfunction in 4,035 patients diagnosed with $\mathrm{BPH}$

artery disease, past myocardial infarction or stroke, heart failure, diabetes and chronic kidney disease), longer time of BPH pharmacotherapy, polytherapy, history of TURP, LUTS severity, nocturia occurrence, and ED (Table 3). The association between DSs and ED presents Figs. 2, 3 and 4.

In the model of backward multivariate logistic regression analysis, it was found that the most important factors associated with the occurrence of DSs are as follows: chronic kidney disease, heart failure, cardiovascular episodes, diabetes, ED, the use of $5 \alpha \mathrm{RI}$ inhibitors, and the severity of LUTS. Secondary or higher or educational level and being married were the only factors reducing the prevalence of DSs (Fig. 5).

\section{Discussion}

This study showed that $22.4 \%$ of patients treated for BPH had DSs, and $71.9 \%$ ED. The occurrence of both DSs and ED was associated with comorbidities (heart failure, coronary artery disease, past myocardial infarction, diabetes, and obesity), as well as with the severity of LUTS, nocturia occurrence, current BPH pharmacotherapy ( $5 \alpha \mathrm{RI}$ ), solitary dwelling, and sedentary life style. Some comorbidities were more strongly affecting ED (hypertension, past stroke), although in others, it was the prevalence of DSs (chronic kidney disease). Furthermore, there was a bidirectional association between DSs and ED; however, the effect of the occurrence of DSs on ED [OR 4.14 (95 \% CI: 2.915.90)] was more manifested than vice versa [3.06 (95\% CI: 2.15-4.36)].

The incidence of DSs in patients with BPH was analysed in few studies. The prevalence of DSs in the American population with LUTS, assessed on the basis of Geriatric Depression Scale (GDS), was similar to that in our study (17.2-22\% vs. $22.4 \%)$ [23, 24]. In accordance with our results, Johnson et al. observed an association between DSs and LUTS severity. However, they suggested that depressed patients report elevated symptoms [23]. The association between DSs and BPH was also confirmed by results obtained in the Taiwanese population, showing development of depression in $2 \%$ of patients diagnosed with BPH during a year, 1.87 times more frequently than in a comparable cohort of men without BPH [24]. Also, little is known about factors that predispose to development of depression in patients with BPH. In Hong Kong and Chinese populations, the factors influencing the prevalence of DSs in patients with BPH were loneliness (widowed, divorced, single status), smoking, the burden of coronary heart disease history, the use of corticosteroids, and moderate or severe LUTS [25, 26]. Loneliness, CVD, and LUTS severity were also factors influencing DSs occurrence in our study. Additionally, Rom et al. [27] showed a relationship between LUTS and DSs in men, using methodology similar to ours (IPSS and BDI). The association between LUTS and DSs is also indirectly confirmed by the studies showing that urinary urgency, frequency, and nocturia have ference with psychological well being [28, 29]. a significant impact on men's lives, degree of worry, inter- 
Fig. 5 Factors influencing the incidence of erectile dysfunction (upper) and depressive symptoms (lower) in the group 4,035 patients diagnosed with benign prostatic hyperplasia. Results of stepwise multivariate backward logistic regression

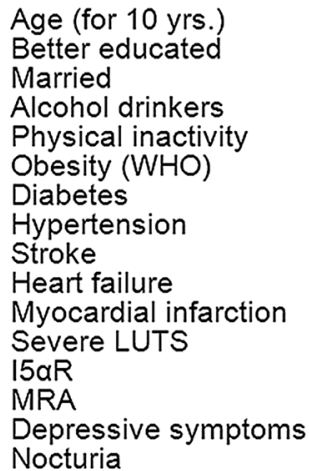

Age (for 10 yrs.) educated

Alcohol drinkers

Physical inactivity

Diabetes

Hypertension

Stroke

Heart failure

Myocardial infarction

Severe LUTS

Depressive symptoms Nocturia

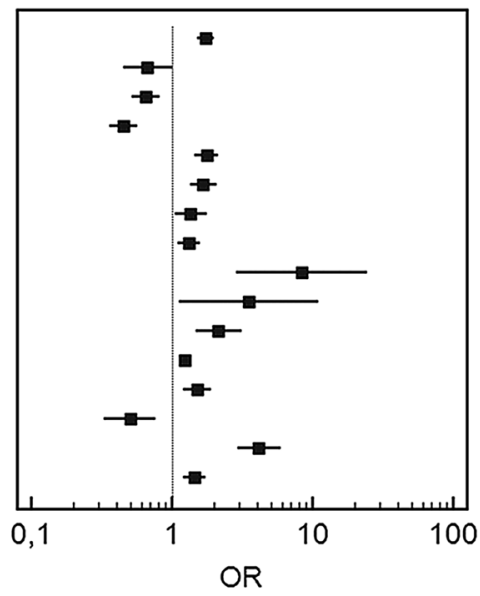

$1.72(1.51-1.96)<0.001$

$0.67(0.45-0.99)<0.05$

$0.65(0.52-0.82)<0.001$

$0.45(0.36-0.56)<0.001$

$1.76(1.45-2.12)<0.001$

$1.66(1.34-2.09)<0.001$

$1.36(1.05-1.76)<0.001$

$1.32(1.10-1.59)<0.01$

$8.35(2.88-24.12)<0.001$

$3.52(1.13-10.99)<0.05$

$2.14(1.46-3.14)<0.001$

$1.22(1.19-1.25)<0.001$

$1.51(1.21-1.88)<0.01$

$0.50(0.33-0.76)<0.001$

$4.11(2.89-5.86)<0.001$

$1.44(1.21-1.73)<0.001$
Age (for 10 yrs.)

Better educated

Married

Physical inactivity

Obesity (WHO)

Diabetes

Heart failure

Myocardial infarction

Chronic kidney disease

Severe LUTS

I5aR

Erectile dysfunction

Nocturia

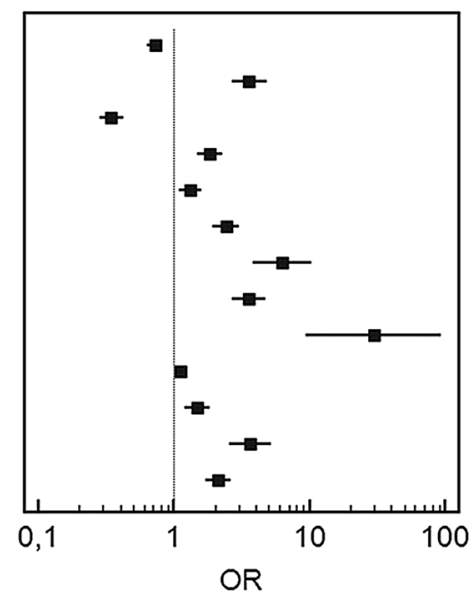

$0.73(0.64-0.82) \quad<0.001$

$3.57(2.65-4.81)<0.001$

$0.34(0.28-0.42)<0.001$

$1.82(1.47-2.25)<0.001$

$1.33(1.09-1.61)<0.01$

$2.42(1.93-3.02)<0.001$

$6.25(3.82-10.24)<0.001$

$3.56(2.68-4.72)<0.001$

$29.66(9.33-94.25)<0.001$

$1.11(1.09-1.13)<0.001$

$1.48(1.20-1.84)<0.001$

$3.62(2.53-5.19)<0.001$

$2.11(1.69-2.64)<0.001$
Our most relevant finding is the association between BPH pharmacotherapy and DSs occurrence. We demonstrated that the use of a 5- $\alpha \mathrm{RI}$ is associated with a 1.52fold higher prevalence of DSs. It is in line with a study showing that the use of finasteride, a 5- $\alpha$ RI might induce development of depression [30]. Furthermore, we found that DSs occur very commonly $(51.8 \%)$ in patients who underwent TURP, more often than in those receiving combine therapy $(31.7 \%)$ even on three drug therapy (with MRA). Contrary, prospective studies show that the level of depression and anxiety decreases after TURP, along with the reduction in LUTS severity [31, 32]. It may be related to increased prevalence of ejaculation disorders after TURP, much higher than in patients treated with 5- $\alpha$ RI [33].

Among other factors explaining the prevalence of DSs in our study population were frequent alcohol consumption (more than three times per week) and nutritional statusmostly obesity. Similar results were obtained previously by other researchers. It was shown that alcohol consumption increases the risk of developing depression [34, 35]. Also, sedentary lifestyle (physical inactivity) and obesity are associated with the prevalence of DSs [36, 37].
Our study demonstrates that at least $90 \%$ of subjects with DSs have ED, the most common sexual dysfunction among elderly men. The impact of this category of sexual dysfunction on sexual activity is significant, and it is obvious that these men seek treatment [38]. In the current study, $30.2 \%$ of patients with ED were treated for this reason.

In line with previously published data, we demonstrated increased prevalence, with advancing age, of ED. Data from the Massachusetts Male Ageing Study showed that the annual incidence of ED was increasing from 12 per 1,000 men aged 40-49 years to 46 per 1,000 men in 60-69 years of age [31]. In the cologne male survey, the prevalence of ED was $19.2 \%$, with a steep age-related increase (2.3-53.4\%) and strong association with comorbidities, e.g. hypertension, diabetes, pelvic surgery, and LUTS [40].

It should be stressed that our study demonstrates that the therapy with 5- $\alpha$ RI has a deteriorative effect on ED, while the use of MRA is beneficial in multiple regression analysis. The beneficial effect of MRA did not appear in simple regression, as this group of drugs is prescribed in patients with severe LUTS. Such aspect has not been studied yet. Hypothetically muscarinic receptor stimulation may 
facilitate erection and ejaculation demonstrated in rats with a transected spinal cord [41]. This observation requires further studies.

ED shows a strong correlation with quality of life. The prevalence of ED increases with the occurrence of concomitant conditions such as heart disease, hypertension, depression, negative mood, problems with relationships, or just inadequate sexual experience [39, 42]. Greenstein et al. [43] found a correlation between the severity of coronary artery disease and ED. In the Massachusetts Male Ageing Study, after adjustment for age, a higher probability of impotence was directly correlated with heart disease, hypertension, diabetes, depression, and their associated medications [44]. The relationship between ED and comorbidities was similar.

Unhealthy lifestyle, including physical inactivity, smoking, and obesity, are among well-known factors affecting the occurrence of ED [45, 46]. However, not all behaviours have deleterious effects. Multivariate logistic regression analysis of our data revealed that physical inactivity and obesity, but not frequent alcohol consumption (more than three times a week) increased the risk of ED. It was already demonstrated that consumption of eight or more drinks/ week significantly reduced the risk of ED [47].

Our study has limitations resulting from methodologycross-sectional design. It should be noted, that the diagnosis of BPH was based on clinical examination (LUTS, DRE, and sonography). Therefore, we cannot exclude that some patients were suffering from undiagnosed prostate cancer. However, due to lack of diagnosis of the cancer, it could not be a factor affecting the level of depression. It should be stressed, that the survey did not include men with diagnosed mental disorders, including depression.

Therefore, the prevalence of depressive syndrome is Polish BPH patients is underestimated. The recently performed PolSenior study revealed that only $13.6 \%$ of elderly with DSs were diagnosed with depression [48]. Taking into account this data, we may estimate the prevalence of DSs among patients with BPH is approximately $26 \%$.

\section{Conclusion}

Prevalence of depressive symptoms in patients diagnosed with BPH is associated with severity of LUTS, erectile dysfunction, nocturia, BPH pharmacotherapy ( $5 \alpha \mathrm{RIs})$, sedentary life style, and comorbidities including obesity.

Acknowledgments This study was organised by Europharma M. Rachtan Sp. Z o.o., which provided assistance in the field of medical services (http://www.europharma.edu.pl/eng/). Dr Magdalena Olszanecka-Glinianowicz and Dr Jerzy Chudek designed the study and are the copyright holders.
Conflict of interest The authors declare that they have no conflict of interest.

Open Access This article is distributed under the terms of the Creative Commons Attribution License which permits any use, distribution, and reproduction in any medium, provided the original author(s) and the source are credited.

\section{References}

1. Berry SJ, Coffey DS, Walsh PC, Ewing LL (1984) The development of human benign prostatic hyperplasia with age. J Urol 132:474-479

2. Parsons JK, Bergstrom J, Silberstein J, Barrett-Connor E (2008) Prevalence and characteristics of lower urinary tract symptoms in men aged $>$ or $=80$ years. Urology 72:318-321

3. Prajsner A, Chudek J, Dąbrowski P, Zejda J, Więcek A (2012) Diseases of the prostate in elderly people in Poland. In: Mossakowska M, Więcek A, Błędowski P (eds) Medical, psychological, sociological and economic aspects of aging in Poland. Termedia, Poznań, pp 317-334

4. Rosen R, Altwein J, Boyle P et al (2003) Lower urinary tract symptoms and male sexual dysfunction: the multinational survey of the aging male (MSAM-7). Eur Urol 44:637-649

5. Hellstrom WJ (2004) Benign prostatic hyperplasia, sexual function, and overall evaluation of the male patient. J Am Osteopath Assoc 104:5-10

6. Rosen RC, Giuliano F, Carson CC (2005) Sexual dysfunction and lower urinary tract symptoms (LUTS) associated with benign prostatic hyperplasia (BPH). Eur Urol 47:824-837

7. van Moorselaar J (2003) LUTS and Sexual Dysfunction: implication for Management of BPH. Eur Urol 2:13-20

8. Brookes ST, Link CL, Donovan JL, McKinlay JB (2008) Relationship between lower urinary tract symptoms and erectile dysfunction: results from the Boston Area Community Health Survey. J Urol 179:250-255

9. Braun MH, Sommer F, Haupt G, Mathers MJ, Reifenrath B, Engelmann UH (2003) Lower urinary tract symptoms and erectile dysfunction: co-morbidity or typical "Aging Male" symptoms? Results of the "Cologne Male Survey". Eur Urol 44:88-594

10. Boyle P, Robertson C, Mazzetta C et al (2003) The association between lower urinary tract symptomms and erectile dysfunction in four centres: the UrEpik study. BJU Int 92:719-725

11. Robertson C, Link CL, Onel E et al (2007) The impact of lower urinary tract symptoms and comorbidities on quality of life: the BACH and UREPIK studies. BJU Int 9:347-354

12. McConnell JD, Roehrborn CG, Bautista OM (2003) Medical Therapy of Prostatic Symptoms (MTOPS) Research Group. The long-term effect of doxazosin, finasteride, and combination therapy on the clinical progression of benign prostatic hyperplasia. $\mathrm{N}$ Engl J Med 349:2387-2398

13. Roehrborn CG, Boyle P, Nickel JC (2002) ARIA3001 ARIA3002 and ARIA3003 Study Investigators. Efficacy and safety of a dual inhibitor of 5-alpha-reductase types 1 and 2 (dutasteride) in men with benign prostatic hyperplasia. Urology 60:434-441

14. Andersson KE, Wyllie MG (2003) Ejaculatory dysfunction: why all alpha-blockers are not equal. BJU Int 92:876-877

15. Montorsi F, Henkel T, Geboers A et al (2010) Effect of dutasteride, tamsulosin and the combination on patient-reported quality of life and treatment satisfaction in men with moderateto-severe benign prostatic hyperplasia: 4-year data from the CombAT study. Int J Clin Pract 64:1042-1051 
16. Desgrandchamps F, Droupy S, Irani J, Saussine C, Comenducci A (2006) Effect of dutasteride on the symptoms of benign prostatic hyperplasia, and patient quality of life and discomfort, in clinical practice. BJU Int 98:83-88

17. Parnowski T, Jernajczyk W (1977) Beck's depression inventory in the rating of mood in normal subjects and in patients with affective disturbances. Psychiatr Pol 11:417-421

18. World Health Organization (2000) Technical report series 894: Obesity: Preventing and managing the global epidemic. Geneva

19. Alberti KG, Zimmet P, Shaw J (2006) Metabolic syndrome-a new world-wide definition. A consensus statement from the international diabetes federation. Diabet Med 23:469-480

20. Beck AT, Steer RA, Ball R, Ranieri W (1996) Comparison of Beck Depression Inventories -IA and -II in psychiatric outpatients. J Pers Assess 67:588-597

21. Barry MJ, Fowler FJ Jr, O'Leary MP et al (1992) The American Urological Association symptom index for benign prostatic hyperplasia. The Measurement Committee of the American Urological Association. J Urol 148:1549-1557

22. Rosen RC, Cappelleri JC, Smith MD, Lipsky J, Peña BM (1999) Development and evaluation of an abridged, 5-item version of the International Index of Erectile Function (IIEF-5) as a diagnostic tool for erectile dysfunction. Int J Impot Res 11:319-326

23. Johnson TV, Abbasi A, Ehrlich SS et al (2010) Major depression drives severity of American Urological Association Symptom Index. Urology 76:1317-1320

24. Huang CY, Chiu KM, Chung SD, Keller JJ, Huang CC, Lin HC (2011) Increased risk of depressive disorder following the diagnosis of benign prostatic enlargement: one-year follow-up study. J Affect Disord 135:395-399

25. Wong SY, Hong A, Leung J, Kwok T, Leung PC, Woo J (2006) Lower urinary tract symptoms and depressive symptoms in elderly men. J Affect Disord 96:83-88

26. Wong SY, Woo J, Leung JC, Leung PC (2010) Depressive symptoms and lifestyle factors as risk factors of lower urinary tract symptoms in Southern Chinese men: a prospective study. Aging Male 13:113-119

27. Rom M, Schatzl G, Swietek N, Rucklinger E, Kratzik Ch (2012) Lower urinary tract symptoms and depression. BJU Int 110:918-921

28. Girman CJ, Jacobsen SJ, Tsukamoto T et al (1998) Health-related quality of life associated with lower urinary tract symptoms in four countries. Urology 51:428-436

29. Trueman P, Hood SC, Nayak US, Mrazek MF (1999) Prevalence of lower urinary tract symptoms and self-reported diagnosed 'benign prostatic hyperplasia' and their effect on quality of life in a community-based survey of men in the UK. BJU Int 83:410-441

30. Rahimi-Ardabili B, Pourandarjani R, Habibollahi P, Mualeki A (2006) Finasteride induced depression: a prospective study. BMC Clin Pharmacol 6:7

31. O'Sullivan M, Murphy C, Deasy C, Iohom G, Kiely EA, Shorten G (2004) Effects of transurethral resection of prostate on the quality of life of patients with benign prostatic hyperplasia. J Am Coll Surg 198:394-403

32. Gourova LW, van de Beek C, Spigt MG, Nieman FH, van Kerrebroeck PE (2006) Predictive factors for nocturia in elderly men: a cross-sectional study in 21 general practices. BJU Int 97:528-532
33. Kaplan SA (2009) Side effects of $\alpha$-blocker use : retrograde ejaculation. Rev Urol 11:14-18

34. Coêlho BM, Andrade LH, Guarniero FB, Wang YP (2010) The influence of the comorbidity between depression and alcohol use disorder on suicidal behaviors in the São Paulo Epidemiologic Catchment Area Study, Brazil. Rev Bras Psiquiatr 32:396-408

35. Boden JM, Fergusson DM (2011) Alcohol and depression. Addiction 106:906-914

36. Yu ZM, Parker L, Dummer TJ (2014) Depressive symptoms, diet quality, physical activity, and body composition among populations in Nova Scotia, Canada: report from the Atlantic Partnership for Tomorrow's Health. Prev Med 61:106-113

37. Olszanecka-Glinianowicz M, Zahorska-Markiewicz B, Kocełak P et al (2009) Depression in Obese Persons Before Starting Complex Group Weight-Reduction Programme. Int J Soc Psychiatry 55:407-413

38. Koskimaki J, Hakama M, Huhtala H, Tammela TLJ (2000) Effect of erectile dysfunction of frequency of intercourse: a population based prevalence study in Finland. J Urol 164:367-370

39. Johannes CB, Araujo AB, Feldman HA, Derby CA, Kleinman KP, McKinlay JB (2000) Incidence of erectile dysfunction in men 40-69 years old: longitudinal results from the Massachusetts Male Aging Study. J Urol 163:460-463

40. Braun M, Wassmer G, Klotz T, Reifenrath B, Mathers M, Engelmann U (2000) Epidemiology of erectile dysfunction: results of the Cologne Male Survey. Int J Impot Res 12:305-311

41. Vargas VM, Torres D, Corona F et al (2004) Cholinergic facilitation of erection and ejaculation in spinal cord-transected rats. Int J Impot Res 16:86-90

42. Araujo AB, Durante R, Feldman HA, Goldstein I, McKinlay JB (1998) The relationship between depressive symptoms and Male erectile dysfunction: cross-sectional results from Massachusetts Male Aging Study. Psychosom Med 60:458-465

43. Greenstein A, Chen J, Miller H, Matzkin H, Villa Y, Braf Z (1997) Does severity of coronary disease correlate with erectile dysfunction?. Int J Impotence Res 9:123-126

44. Feldman HA, Goldstein I, Hatzichristou DG, Krane RJ, McKinlay JB (1994) Impotence and its Medical and psychological correlates: results of the Massachusetts Male Aging Study. J Urol 151:54-61

45. Glina S, Sharlip ID, Hellstrom WJ (2013) Modifying risk factors to prevent and treat erectile dysfunction. J Sex Med 10:115-119

46. Parsons JK (2007) Modifiable risk factors for benign prostatic hyperplasia and lower urinary tract symptoms: new approaches to old problems. J Urol 178:395-401

47. Cheng JY, Ng EM, Chen RY, Ko JS (2007) Alcohol consumption and erectile dysfunction: meta- analysis of population-based studies. Int J Impot Res 19:343-352

48. Broczek K, Mossakowska M, Szybalska A, Kozak-Szkopek E, Ślusarczyk P, Wieczorowska-Tobis K, Parnowski T (2012) The occurrence of depressive symptoms in elderly. In: Mossakowska M, Więcek A, Błędowski P (eds) Medical, psychological, sociological and economic aspects of aging in Poland. Termedia, Poznań, pp 123-136 